\title{
Short communication Why patient representation might harm science?
} Jim Cassidy

Beatson Oncology Unit, Department of Medical Oncology, University of Glasgow, Switchback Road, Glasgow, G61 1BD, UK

Corresponding author: Jim Cassidy, j.cassidy@beatson.gla.ac.uk

Published: 20 December 2007

This article is online at http://breast-cancer-research.com/content/9/S2/S4 (c) 2007 BioMed Central Ltd

\section{Introduction}

The invitation to discuss this topic brings with it some trepidation. In the current climate it is not 'politically correct' to take the stance that patients should be excluded from any aspect of their care. So, from the outset I must declare that I have some sympathy with patient representation, but I can also see some problems and pitfalls. For the purposes of this debate I have chosen to focus on these aspects, but will try to balance this as we proceed.

Clinical science in the form of clinical trials is a slow and laborious process. From concept to initiation, even a simple clinical trial can take several years and involves repeated applications for funding, peer review, ethics review and several other processes. The recent adoption of European Union directives on clinical trials has also added to this burden. Principal investigators are usually highly qualified and experienced individuals. They have taken the decision to lead research because they are committed to making a difference to patient care; otherwise, they could live out their working lives in the National Health Service (in the UK context) or in private practice (in most other countries). Although many would contend that they only do it because there is something in it for them - perhaps peer approval, fame, or power - I doubt that those rewards alone are sufficient motivation. This is borne out by the fact that clinical trialists are always in the minority of any professional health care grouping.

\section{Why would we wish to involve patients?}

Consultation of user groups/clients/customers is currently in vogue in many aspects of life. In most cases this is useful to obtain consumer advice about product or service qualities. Although one could draw parallels between these individuals and patients, I would contend that patients are not actually customers. This is because, in my view, becoming a customer is a voluntary process, whereas becoming a patient is as far from voluntary as one could imagine. There is also the implication in consumer feedback that things may change for the better as a result of that feedback; I am not convinced that this is realistic in many aspects of patient care. The
Breast Cancer Research 2007, 9(Suppl 2):S4 (doi:10.1186/bcr1802)

customer can also shop elsewhere if they are unhappy with the product; once again, I am unconvinced that that fits with reality when one considers the provision of health care. Most of us are not within reasonable travelling distance of suitable alternatives, especially if one considers therapy for most lifethreatening conditions.

\section{What could patient representation add to this already rigorous process?}

The patient may be able to bring to the table some consideration of project feasibility or acceptability. Although the principal investigators usually work in the same environment and one might expect them to have a clear view on these matters, I would concede that this may not always be true. However, does the patient representative really know that much more? Each individual will bring their own personal bias and in some cases they have some 'axe to grind'. Later, I shall return to this issue of how representative the patient can be of the population in question.

The patient may also have the role of 'protector' in some circumstances. Investigators can be so wrapped up in their own ideas that they fail to see the risks and potential hazards to patients (physical or psychological). I doubt that this is in any way deliberate or premeditated. This role is also one of the functions of ethics committees, so perhaps we do not need extra protectors.

\section{What damage could they do?}

The selection (or self-selection) of a patient representative causes me concern. How can they be truly representative? They tend to be well educated professional people - not quite the average person in my clinical practice in Glasgow. Then, they get sent on various training courses and are offered psychological support. They also become experienced - and some might say 'tamed' - by association with medical and allied health care professionals. This must surely influence their opinions over time. This may not be damaging, but it may take away any supposed value of the representative. 
A patient representative may have a particular issue from their own experience (or that of a loved one). This may cloud their objectivity when attempting to generalize this experience to a population. Extreme risk aversion may be an example. Because all therapies we use can be toxic - some even fatal it is impossible to avoid all risk in clinical practice. Excessive focus on just one aspect of outcome (such as quality of life) may lead to over-emphasis on this point in trial design.

Patient representatives might make the process slower. Peer review is already an extensive part of the trial development process. Any further steps added will inevitably slow us down and further diminish the clinical trial portfolio.

Their involvement is not free. They usually are paid and their support structure is also financially subsidized. Who pays for this? Could the monies have been used to support more trials?
Finally, it may be more difficult to design and execute clinical trials that attempt to prove a principle and may have little or no therapeutic benefit for the participants, the simplest example being pharmacokinetic/pharmacodynamic studies in humans.

\section{Conclusion}

Patient representation sounds like a good idea, but it does have significant risks and pitfalls for clinical science.

\section{Acknowledgement}

This article has been published as part of Breast Cancer Research Volume 9 Supplement 2, 2007: Controversies in Breast Cancer. The full contents of the supplement are available online at http://breastcancer-research.com/supplements/9/S2. 